\title{
Smartphone Dependency and Its Impact on Purchase Behavior
}

\author{
Amran Harun ${ }^{1}$, Liew Toh Soon ${ }^{1}$, Abdul Wahid Mohd Kassim ${ }^{1} \&$ Rini Suryati Sulong ${ }^{1}$ \\ ${ }^{1}$ Faculty of Business, Economics and Accountancy, Universiti Malaysia Sabah, Jalan UMS, Kota Kinabalu, \\ Sabah, Malaysia \\ Correspondence: Abdul Wahid Mohd Kassim, Faculty of Business, Economics and Accountancy, Universiti \\ Malaysia Sabah, Jalan UMS, 88400 Kota Kinabalu, Sabah, Malaysia Tel: 60-13-856-0031. E-mail: \\ awmk66@gmail.com; abdulwah@ums.edu.my
}

Received: July 24, 2015 Accepted: September 2, 2015 Online Published: September 21, 2015

doi:10.5539/ass.v11n26p196

URL: http://dx.doi.org/10.5539/ass.v11n26p196

\begin{abstract}
People nowadays seem to become dependent towards smartphone due to its convenience, great camera features, easy applications' installations, and more importantly, it can do most of the computer functions on the go. Significantly, smartphone usage in Malaysia is growing enormously and has become a significant and lucrative industry. This study aims to understand the antecedents and the outcome of the smartphone dependency among smartphone consumers. Two theories - the theory of uses and gratification and the media dependency theorywere used as the theoretical basis for this study, in order to determine the motivations to use a smartphone and to define dependency and its outcome. The antecedent variables were convenience, social need and social influence; and all of these dimensions are conceptualized as one-dimensional. The outcome of dependency on smartphones was expected to be the purchase behavior. Data analyses were based on 226 valid questionnaires that were collected among smartphone users. The result from the Confirmatory Factor Analysis of Partial Least Square (PLS) shows that only social needs and social influence significantly influenced the smartphone dependency among consumers, therefore indicating that these two factors are important to influence dependency on the smartphone. In addition, the analysis also verifies that the purchase behavior is the outcome of the dependency on the smartphone. Based on these results, marketers could focus on creating dependency among consumers on smartphone usage based on the consumers' social need, which eventually will promote future purchase behavior in the long run. More importantly, understanding social influences as antecedents
\end{abstract}

Keywords: dependency on smartphone, purchase behavior, theory of uses and gratification, theory of media dependency

\section{Introduction}

Consumers nowadays have slowly become dependent on mobile phones. Today's mobile phones are no longer only used for making and receiving calls, but rather includes various useful features and thus making them known more as smartphones. It is a common sight to see people in a queue or while waiting for a train, bus, and airplane to have a smartphone in their palm to pass the time. Some, even at a coffee table, gathering with friends would keep browsing social websites to update their status. Lim, Wong, Zolkepli and Rashvinjeet (2012) reported that there is even such a trend that youngsters today would sit around together for dinner, but none of them are talking and instead had their eyes glued to their mobile phones texting or surfing. On top of that, smartphones with the great camera features have even made consumers to prefer and be dependent on smartphone camera usage due to its convenience. A smartphone enables us to install applications which vary from social networking apps, gaming, work or information apps. As a result, it is important for academics and marketers to understand the underlying causes and outcomes behind this smartphone dependency phenomenon in order to understand consumer behavior; as well as for marketers to sustain sales of smartphone and its market share. Significantly, to identify and understand the important factors which influence dependency on the smartphone and the expected outcome of the dependency-purchasing behavior, two theories will be used namely Theory of Uses and Gratification and Theory of Media Dependency. The latter was used to explain dependency and its outcome (purchasing behavior) whilst Theory of Uses and Gratification was used to justify and explain factors that motivate people to depend on smartphone. 


\section{Media Dependency Theory}

The media dependency theory focuses on the consumer dependency to satisfy the goals (Patwardhan \& Yang, 2003). This theory states that media dependency is where the satisfaction of needs or the attainment of goals by individuals upon the resources of the party or media is met (Patwardhan \& Yang, 2003). The individual will then develop a dependency with the media to fulfill their goals and some of these goals would require access to resources controlled by the mass media (Ball-Rokeach, 1985). Loges (1994) suggested media system dependency is not an exclusive media effect and many outside influences may enhance or restrict the dependency relation. Together with the categories or goals which concern with the dependency of the media, other factors can intensify or reduce media dependency as well, such as demographics, exposure and affinity towards the media (Mafe \& Blas, 2006; Mafe \& Blas, 2008). On the other hand, Alcaniz, Mafe, Manzano and Blas (2008) reported that media dependency will change as the utility of media resources change, which refers to the more usefulness of the media being perceived, the more dependent on the media will be.

$\mathrm{Lu}$ and Wang (2008) suggested that internet addiction or internet dependence is viewed as a psychological dependence on or a behavior action to the Internet. The researchers show that dependency and addiction were about the same. In their research on internet online game addiction, several symptoms of internet addiction were identified; which included the increased length of time online, unpleasant feeling when offline or obsessive thinking about the internet, having occupational or relationship problem and deceit. Hooper and Zhou (2007) discussed dependency (in relation to mobile phone usage) as the regular use of mobile phone which becomes a necessity to their lives and the tendency to switch it on all the time. In a research by Balahkrishnan and Raj (2012) they found that most of their respondents cannot go anywhere without their mobile phone and felt distressed when they do not have their phones with them. They define this as mobile phone attachment. The author's findings further reported that most of the respondents will be angry and frustrated when they cannot use their phone and could not manage their lives without their phones. Balahkrishnan and Raj's findings (2012) are almost similar to what was suggested by Hooper and Zhou (2007). Furthermore, based on the media dependency theory, dependency on media will lead to future purchase behavior. In this context of research, consumer dependency on smartphone is being conceptualized as having the propensity of high usage, being engaged and unwilling to be apart from it (Ting et al., 2011).

\subsection{Uses and Gratification Theory}

The uses and gratification theory can be helpful in explaining why people choose a certain technology or service; how they use it and the outcomes that they feel they have gained from the experience (Auther, 2007). According to $\mathrm{Wu}$ et al. (2010), there were some important assumptions proposed for this theory; firstly, people are active in choosing media based on their needs, secondly, people choose media based on their wants and interest because they have alternate choice to fulfill their needs, and lastly the communication behavior was different from others because of social and psychological factors. Leung (2007) discussed that the basic needs will interact with personal characteristics and the social environment of the individual and this interaction would produce different motives and gratifications behaviors that can come from using the media or other activities.

The general conclusion of the theory of use and gratification studies is that the gratification sought motivates the use of a particular medium in an audience (Leung, 2007). Wei (2008) reveals that audiences are aware of their social and psychological needs and will actively seek the media to fulfill them. The theory of uses and gratification measures not only the internet, but also the unique user interface of the mobile device (Stafford and Gillenson, 1994). The audience is often attempting to satisfy certain psychological needs such as surveillance, information-seeking, entertainment, personal identity or companionship (Leung, 2007; Leung \& Wei, 1998). Sociability, instrumentality, reassurance, entertainment, acquisition, and time management were some of the common motives for the use of the telephone (Leung \& Wei, 1998; Leung 2007). Leung (2007) further found that gratification use of the short messaging system (SMS) in mobile phones were motivated by its convenience, low cost, utility for coordinating, mobility, immediacy, entertainment, relaxation, fashion or status, and intrinsic factor of sociability and affection. These findings are in line with the findings from Leung and Wei (2000) on mobile phone usage.

The uses and gratification theory had been successfully applied to various new media that are related to communication technologies (Wu et al., 2010). According to Mafe and Blass (2008) this theory has become one of the most influential theories in the study of mass media to better understand what the media content needs. As a result, this theory is applicable to explain the current research framework on mobile or smartphone usage since it is very closely related with media and mass communication. Based on the uses and gratification theory, consumers were motivated to use mobile phones or smartphones due to its convenience, sociability as well as 
entertainment. This motivation to use can further lead to their dependency on smartphone and lead to future purchase behavior.

\subsection{Antecedents of Smartphone Dependency}

\subsubsection{Convenience}

Brown (1993) reported that convenience was anything that adds to one's comfort or saves work: useful, handy or helpful device, article or service. He further suggested that convenience is a multidimensional construct with a suggested six classes of convenience. The six classes suggested were time utilization, accessibility, portability, appropriateness, handiness and avoidance of unpleasantness. Berry, Seiders and Grewal (2002) suggested a conceptual model of service convenience which consists of five constructs. These constructs are known as the decision convenience (i.e. customers who desire a particular performance devote time and effort to deciding how to obtain the particular performance), access convenience (i.e. customers' perceived time and effort expenditures to initiate service delivery), transaction convenience (i.e. customers' perceived expenditures of time and effort to effect a transaction), benefit convenience (i.e. customers' perceived time and effort expenditures to experience the service's core benefits), and post-benefit convenience (i.e. customer's perceived time and effort expenditures when reinitiating contact with a firm after the benefit stage of the service).

According to Osman et al. (2011), a smartphone offered advanced computing power and connectivity which literately is a handheld computer that is powerful enough to deliver various functionalities comparable to a computer. Smartphones allow users to check e-mails, keep track of appointments and maintain a calendar; whereas the newer generation of smartphones enable users to handle numerous tasks more efficiently and effectively (Holub, Green, \& Valenti, 2010). Holub et al. (2010) gave an example of tax practitioners who are able to receive e-mail from a client even if they are not in the office which enabled them to provide tax advice to clients thus making their job more convenient and effective. Karlson, Meyers, Jacobs, Johns and Kane (2009) suggest that information workers often manage several different computing devices (PC and smartphone) to balance convenience, mobility, input efficiency, and content readability throughout their day. According the author, these information workers transfer activities and tasks between devices (PC and smartphone) of vastly differing capabilities and some would use their smartphone to work as a primary device until using a PC is necessary. Harvel (2006) suggested that the idea behind convenient for designing an application has to be made easy and people will use it. It has to consistently respond towards "ease of use" and "time-saving" (Harvel, 2006), in which it will aid to the user's job performance (Park \& Chen, 2007). Convenience is normally related to people's perception of time scarcity and value time related issue (Berry et al., 2002) which lead to the consumer need of high convenience (Ting et al., 2011). Hence, in this research context, convenience refers to time saving and usefulness of usage on smartphone, which is in line with Ting et al. (2011) as a single dimension construct. The usefulness is in performing various PC-related tasks and ability to complete tasks quickly allowing for greater time saving.

Hahn (2010) reported the twin function of a mobile phone as a laptop and as a phone has provided an increase usage rate of the smartphone users. This increase usage rate has shown a dependency impact on the users. Apart from that, Karlson et al. (2009) showed that engineers in the software industry would prefer to use their smartphone at work rather than their PC. On top of that, Holub et al. (2010) reported that tax practitioners had their smartphone as a moving office, which made them more effective to work and respond to emails. These examples strongly suggested the increase usage of smartphone had led to people's dependency on smartphone. Ting et al. (2011) research finding showed that the convenience factors of smartphone had positively affected consumer's dependency on smartphones. Therefore, it is hypothesized that:

$\mathrm{H}_{1}$ : Convenience has a positive relationship with consumers dependency on smartphone usage.

\subsubsection{Social Needs}

According to Maslow's hierarchy of needs, there are five sets of goals which are referred to as 'basic needs' (Maslow, 1943). The basic needs in Maslow's hierarchy of needs are physiological, safety, love or sense of belonging, esteem and self-actualization needs (Maslow, 1943; Tikkanen, 2009). Stephen (2000) suggested that if both the physiological and safety needs are being satisfied, a new set of needs emerge which are the needs for love, affection and belongingness. This is classified as the social needs (Stephen, 2000). Based on the uses and gratification theory, the use of mobile phone or telephones is categorized into two: intrinsic and instrumental where intrinsic are towards social oriented and social motives (Leung \& Wei, 1998; Balahkrishnan \& Raj, 2012; Leong \& Wei, 2000). Leung and Wei (2000) found out that the use of mobile phone is for affection and sociability, such as chatting, gossip, keeping family contacts and having a sense of security. Women have intrinsic use of telephone as they are more concerned about family and use of telephone helped owners feel less 
lonely and more secure (Leung \& Wei, 1998). This is similar to what suggested by Balahkrishnan and Raj (2012) that intrinsic as communication for the purpose of companionship or reassurance. They also reported that mobile phones have become a necessary part of social communication through the maintenance of key social network. Mobile phones keep social interaction with friends and family as well as a precaution to the security aspect for emergency purposes (Balahkrishnan \& Raj, 2012; Wei, 2008). Ting et al. (2011) also suggested that the uses of smartphone are to fulfill the social need of communicating with family and friends as well as affiliation groups. They can stay connected through integrated live chat in the smartphone or simple access to social sites such as Facebook or Twitter to stay connected. Social needs in this research context will be similar to what was suggested by Ting et al. (2011). It will refer to as users of smartphone to fulfill their social need to communicate and stay connected with others.

Ting et al. (2011) reported that interaction or social networking together with live chatting has been made available and can be enabled through smartphones. This will lead to one's increase usage of smartphones and the dependency to it. Leung and Wei (2000) found out that the use of mobile phone is for affection and sociability, such as chatting, gossip, keeping family contacts and having a sense of security. On the other hand, the uses of mobile phone or telephones are towards social oriented and social motives (Balahkrishnan and Raj, 2012). Ting et al. (2011) in their research further showed a positive relationship between social needs and dependency on smartphone. Hence, it is proposed that:

$\mathrm{H}_{2}$ : Social needs has a positive relationship with consumers dependency on smartphone usage.

\subsubsection{Social Influence}

In a research by Weber and Villebonne (2002), social influence was defined as a cultural environment that is an external variable that will influence one's behavior as well as influence the reasons why and how people live. They stress that this external cultural environment is important for strategic marketing plan because society exerts a constant and persuasive influence on its members. According to Lu and Wang (2008), social influence has a profound impact on the user's perception and behavior which can be divided into two distinct constructs: subjective and descriptive norms. The researchers described subjective norms as the social pressures to perform or not to perform a specific behavior and descriptive norms as the perception of the attitudes and behaviors of significant others. When we observe other people performing a certain behavior, we are more likely to believe that is a sensible thing to do (Lu \& Wang, 2008). Previous studies that have focused on subjective norms perceive it as social pressures an individual faces when deciding whether to behave in a certain way (Lu \& Wang, 2008; Pookulangara \& Koesler, 2011). Pookulangara and Koesler (2011) suggest that people may choose to perform a behavior to comply with important referents even if they are not favorable. Bearden, Metemeyer and Teel (1989) suggest that a subjective norm is where people would act or actually act according to their importance referent like friends, family, or society in general. Manson, Conrey and Smith (2007) suggested that the social influences are divided into two fundamental components, namely the sources and target of influence as well as time. The author describes social influence involving many sources and targets as people converse with groups of friends. Hence it is seen to be multidirectional, which involves multiple sources and multiple targets of influence. On the other hand, the second component of time is an inherently dynamic process and is not limited to a single time point only. Social influence affects the ways other people affect one's beliefs, feelings and behavior (Manson et al., 2007). Social influence in this research is conceptualized to be the way other people or the environment will affect one's belief or behavior (Weber \& Villebonne, 2002). This definition is in line with Ting et al. (2011).

Klobas and Clyde (2001) found that social influence from family and friends, teachers, colleagues, students and many more can influence the outcome of the usage of the internet. Auter (2007) also added that friends and family are among the important social influence to the usage of mobile phone. These usages are linked with dependency (high usage) in the context of this research. If smartphone made a good impression on others, consumer dependency on them will increase and consequently lead to a positive word of mouth communication to others (Ting et al., 2011). The research finding by Ting et al. (2011) also reported a positive relationship of the social influence and the dependency of smartphone. Based on the discussion, it is proposed that:

$\mathrm{H}_{3}$ : Social influence has a positive relationship with consumers dependency on smartphone usage.

\subsection{Outcome of Smartphone Dependency}

\subsubsection{Purchase Behavior (Continuous Purchase)}

Different from purchase intention, purchase behavior is in which the product is purchased with some degree of regularity (Hawkins, Mothersbaugh, \& Mookerjee, 2010). According to Newberry, Klemz and Boshoff (2003), 
purchase intentions were seen as swift purchase and were in the near term whereas purchase behaviors were more towards long term of purchasing. Consumer purchase behavior can be used to define customer loyalty where there is a repeat purchase behavior or a repeat patronage with a favorable attitude (Kong, 2006). According to Oliver (1999) these repurchase intentions or loyalty had been defined as a deeply commitment to rebuy and patronized towards a product consistently in the future causing repetitive purchase of the same brand despite influence and marketing effort of rival competitors. He further claims that consumer loyalty can transpire at four different levels: cognitive, affective, conative (behavior intention), and action (actual behavior). Haverila (2011) research on repurchase intention of mobile phone focuses on the conative (behavior intention) as he reported that conative or behavior intention can predict behavior of mobile phone usage.

In a research on internet addiction by $\mathrm{Lu}$ and Wang (2008), they conceptualized loyalty as comprising of two dimensions: attitudinal and behavioral characteristic. The behavioral aspect refers to the intention to make repeated purchase and the attitudinal aspect refers to the favorable attitude toward or preference for certain services or certain product or firm. Uncles, Dowling and Hammond (2003) proposed three conceptualized models for loyalty. First, loyalty as primarily an attitude that sometimes leads to a relationship with the brand where people's beliefs and positive feelings with the brand lead to repeat patronage. Second, loyalty mainly expressed in terms of how it reveals behavior, defined mainly with reference to the pattern of past purchases of a consumer. Third, refers to buying moderated by individual's characteristics, circumstances and the purchase situation. Research findings by Ting et al. (2011) on dependency of smartphone and impact of purchase behavior, reported that the consumers' past experience will lead to their future purchase behavior. They perceived purchase behavior as a behavior intention that will lead to future purchase of smartphone; which, in turn, will lead them to use a smartphone based on their past experience. On the other hand, a consumer's past positive experience on certain media would lead to future purchase behavior as well (Kuhlmeier \& Knight, 2003). Research by Pilstrom and Brush (2008) take the intention to repurchase, word of mouth communications and willingness to pay behavior as a separate construct in which traditionally had been used as the dimensional measure for behavioral intention. Their study is on word of mouth, willingness to pay and repurchase intention as an outcome of perceived value; and this allows the examination on differential individual effects of the perceived value dimensions on each behavioral intention (Lin, Sher, \& Shih, 2005). Hence, in this research purchase behavior is conceptualized as a behavior intention for future repurchase or repeat purchase and use of smartphone (Kong, 2006; Ting et al., 2011).

Ting et al., (2011) suggested that consumers learn quickly from their prior experience on smartphone usage which will be a guide or evaluation for them to decide their next purchase. However, further research findings showed that there is a positive relationship of dependency on smartphone and purchase behavior on smartphone. Whereas Patwardhan and Yang (2003) also showed that the orientation dimension of dependency could predict actual online purchase. On the other hand, research done by Mafe and Blas (2006) on internet dependency and purchase intention, found that internet dependency has a positive influence on future behavior. In addition to that, Alcaniz et al. (2008) also reported that online information dependency significantly leads to future online purchase intention. Therefore, this study hypothesized that:

$\mathrm{H}_{4}$ : Dependency of consumer on smartphone has a positive relationship with their purchase behaviour.

\section{Research Methodology}

The targeted samples were 260 respondents who own and use a smartphone. Sample selections were based on those who were age 18 and above. This was because people from this age onwards were being perceived as an adult with higher purchasing power and the ability to make decisions on their own on the preference of choice and purchase. The data collected from this study was analyzed using Smart Partial Least Square 2.0. The following research model was used in this study, as shown in Figure 1. 


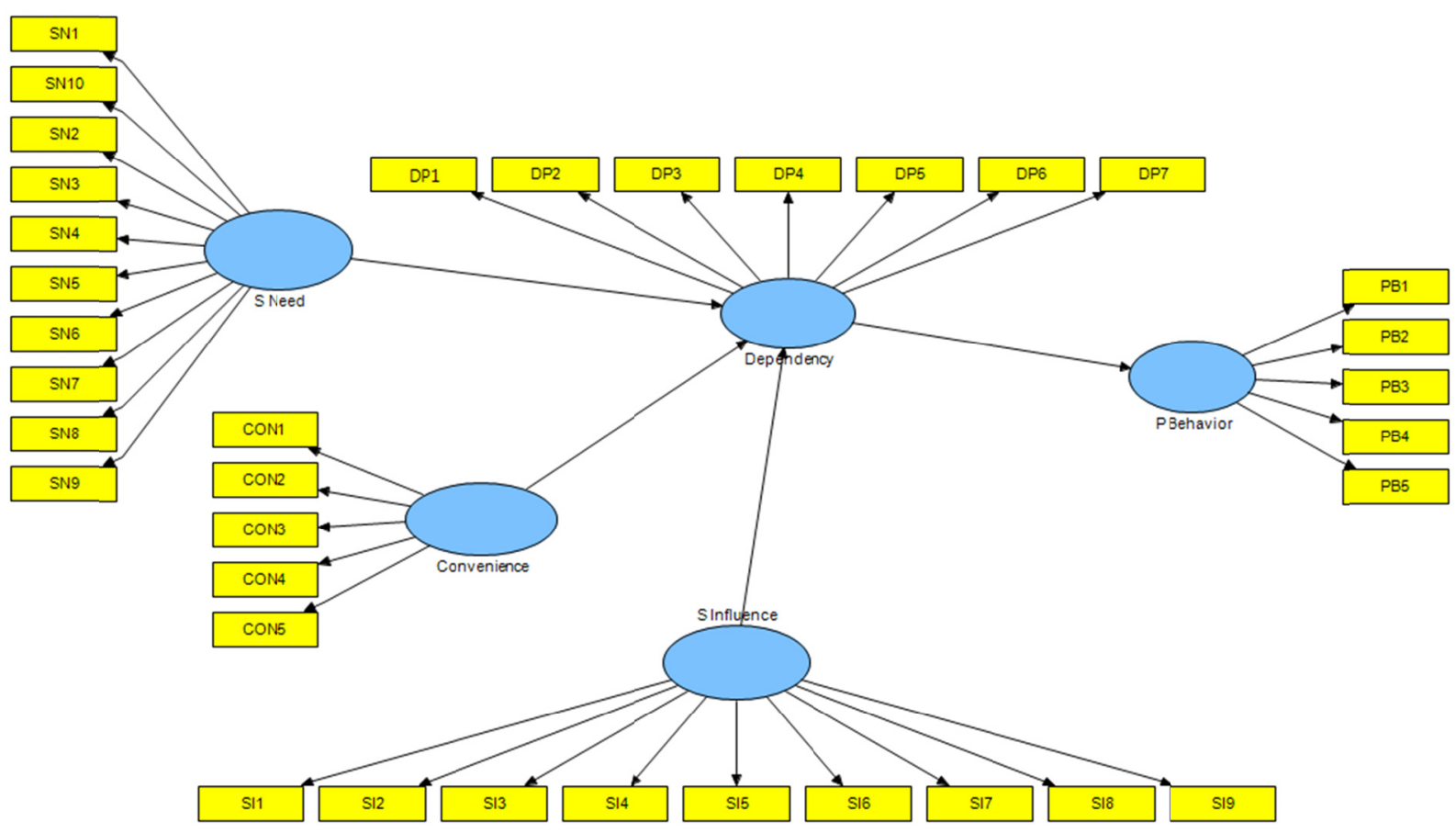

Figure 1. The research model

\section{Measurement instrument}

\subsection{Common Method Variance}

Prior to further analysis, common method variance (CMV) needs to be tested when data are collected through self-reported questionnaires and, particularly, when both the criterion and predictor variables are acquired from the same person (Podsakoff, MacKenzie, Lee, \& Podsakoff, 2003). CMV refers to variance credited to the measurement method instead of variance explained by the study's construct. The existence of CMV can be detected if one principal factor counts for the majority of the variance explained (Podsakoff and Organ 1986). As such, CMV was first to be tested to obtain rigorous empirical evidence in this study. An exploratory factor analysis was performed by entering all measurement items, findings revealed that the largest variance explained by an individual factor was $25.057 \%$ (see Table 1). The findings confirmed that CMV was not considered a significant problem for this study.

Table 1. Measurement model Total Variance Explained

\begin{tabular}{|c|c|c|c|c|c|c|}
\hline \multirow{2}{*}{ Component } & \multicolumn{3}{|c|}{ Initial Eigenvalues } & \multicolumn{3}{|c|}{ Extraction Sums of Squared Loadings } \\
\hline & Total & $\%$ of Variance & Cumulative \% & Total & $\%$ of Variance & Cumulative $\%$ \\
\hline 1 & 9.020 & 25.057 & 25.057 & 9.020 & 25.057 & 25.057 \\
\hline 2 & 3.343 & 9.286 & 34.342 & & & \\
\hline 3 & 2.781 & 7.726 & 42.068 & & & \\
\hline 4 & 2.269 & 6.304 & 48.372 & & & \\
\hline 5 & 1.981 & 5.502 & 53.874 & & & \\
\hline 6 & 1.540 & 4.277 & 58.150 & & & \\
\hline 7 & 1.255 & 3.487 & 61.638 & & & \\
\hline 8 & 1.171 & 3.253 & 64.891 & & & \\
\hline 9 & 1.111 & 3.086 & 67.977 & & & \\
\hline 10 & .988 & 2.743 & 70.720 & & & \\
\hline 11 & .938 & 2.606 & 73.326 & & & \\
\hline
\end{tabular}




\begin{tabular}{|c|c|c|c|c|c|c|}
\hline \multirow{2}{*}{ Component } & \multicolumn{3}{|c|}{ Initial Eigenvalues } & \multicolumn{3}{|c|}{ Extraction Sums of Squared Loadings } \\
\hline & Total & $\%$ of Variance & Cumulative \% & Total & $\%$ of Variance & Cumulative \% \\
\hline 12 & .843 & 2.340 & 75.667 & & & \\
\hline 13 & .784 & 2.177 & 77.843 & & & \\
\hline 14 & .731 & 2.031 & 79.874 & & & \\
\hline 15 & .670 & 1.861 & 81.735 & & & \\
\hline 16 & .592 & 1.643 & 83.378 & & & \\
\hline 17 & .549 & 1.524 & 84.902 & & & \\
\hline 18 & .533 & 1.482 & 86.384 & & & \\
\hline 19 & .499 & 1.386 & 87.770 & & & \\
\hline 20 & .445 & 1.236 & 89.006 & & & \\
\hline 21 & 439 & 1.220 & 90.226 & & & \\
\hline 22 & .416 & 1.156 & 91.382 & & & \\
\hline 23 & .362 & 1.005 & 92.387 & & & \\
\hline 24 & .351 & .974 & 93.361 & & & \\
\hline 25 & 294 & .816 & 94.178 & & & \\
\hline 26 & .289 & .802 & 94.980 & & & \\
\hline 27 & .256 & .712 & 95.692 & & & \\
\hline 28 & .239 & .663 & 96.355 & & & \\
\hline 29 & .229 & .637 & 96.992 & & & \\
\hline 30 & .196 & .545 & 97.537 & & & \\
\hline 31 & .192 & .534 & 98.070 & & & \\
\hline 32 & .176 & 488 & 98.558 & & & \\
\hline 33 & .161 & .448 & 99.006 & & & \\
\hline 34 & .141 & .392 & 99.398 & & & \\
\hline 35 & .115 & .320 & 99.718 & & & \\
\hline 36 & .102 & .282 & 100.000 & & & \\
\hline
\end{tabular}

Extraction Method: Principal Component Analysis

\section{Analysis and Results}

\subsection{Assessment of the Measurement Model}

In order to obtain valid and reliable results, this study followed the two-step approach as suggested by Chin (1998). The assessment of the measurement model was done using both convergent and discriminant validity analysis. Factor loadings, cross-loading, composite reliability and average variance extracted were used to assess convergence validity. Therefore, the process was to confirm the convergent validity before proceeding to test the structural model and hypothesis. First, the measurement model was tested for convergent validity. The convergent validity is defined as the degree to which multiple items converge in measuring the concept of construct (Bagozzi et al., 1991; Hair et al., 2010). This was assessed through cross loadings, factor loadings, composite reliability (CR) and average variance extracted (AVE) (Hair et al., 2010). This means that if all the items are significantly important in measuring their constructs, the loadings and cross-loading for all items should not be lower than 0.5 (Hair et al., 2010). While, the composite reliability values are at least 0.7 and the average variance extracted (AVE) are at least 0.5 , then the convergent validity can be confidently confirmed (Bagozzi et al., 1991; Hair et al., 2010). As seen in Table 2 and Table 3, the loadings and cross loading for all items exceeded the recommended value of 0.5 (Hair et al., 2010). While, the composite reliability value of all the constructs exceeded the cut-off value of 0.7 and all the values of AVEs are more than the 0.5 threshold. Thus, one can confirm that the measurement model possesses an adequate level of convergent validity. Therefore, we can conclude that convergent validity has been established. 
Table 2. Cross-Loading of the Items

\begin{tabular}{|c|c|c|c|c|c|}
\hline & Convenience & Dependency & P Behavior & S Influence & S Need \\
\hline CON1 & 0.761 & 0.243 & 0.320 & 0.132 & 0.317 \\
\hline CON2 & 0.767 & 0.222 & 0.326 & 0.170 & 0.276 \\
\hline CON3 & 0.678 & 0.169 & 0.322 & 0.118 & 0.203 \\
\hline CON4 & 0.690 & 0.188 & 0.312 & 0.164 & 0.282 \\
\hline CON5 & 0.707 & 0.183 & 0.276 & 0.193 & 0.273 \\
\hline DP1 & 0.164 & 0.643 & 0.213 & 0.276 & 0.195 \\
\hline DP2 & 0.319 & 0.725 & 0.501 & 0.269 & 0.420 \\
\hline DP4 & 0.237 & 0.705 & 0.558 & 0.203 & 0.391 \\
\hline DP5 & 0.139 & 0.804 & 0.379 & 0.278 & 0.319 \\
\hline DP6 & 0.123 & 0.770 & 0.351 & 0.342 & 0.273 \\
\hline DP7 & 0.195 & 0.722 & 0.194 & 0.247 & 0.189 \\
\hline PB1 & 0.186 & 0.280 & 0.686 & 0.241 & 0.326 \\
\hline PB2 & 0.316 & 0.391 & 0.820 & 0.193 & 0.310 \\
\hline PB3 & 0.251 & 0.346 & 0.603 & 0.136 & 0.269 \\
\hline PB4 & 0.401 & 0.503 & 0.817 & 0.265 & 0.351 \\
\hline PB5 & 0.397 & 0.483 & 0.809 & 0.184 & 0.373 \\
\hline SI2 & 0.101 & 0.239 & 0.152 & 0.751 & 0.250 \\
\hline SI3 & 0.067 & 0.274 & 0.120 & 0.754 & 0.220 \\
\hline SI4 & 0.216 & 0.312 & 0.391 & 0.682 & 0.365 \\
\hline SI7 & 0.126 & 0.224 & 0.090 & 0.713 & 0.141 \\
\hline SI9 & 0.248 & 0.224 & 0.154 & 0.663 & 0.246 \\
\hline SN1 & 0.236 & 0.240 & 0.289 & 0.140 & 0.746 \\
\hline SN10 & 0.308 & 0.390 & 0.428 & 0.327 & 0.789 \\
\hline SN2 & 0.263 & 0.278 & 0.279 & 0.262 & 0.695 \\
\hline SN3 & 0.273 & 0.192 & 0.217 & 0.117 & 0.663 \\
\hline SN4 & 0.217 & 0.219 & 0.236 & 0.152 & 0.756 \\
\hline SN5 & 0.309 & 0.418 & 0.390 & 0.300 & 0.852 \\
\hline SN6 & 0.202 & 0.285 & 0.234 & 0.174 & 0.691 \\
\hline SN7 & 0.208 & 0.331 & 0.344 & 0.250 & 0.707 \\
\hline SN8 & 0.375 & 0.387 & 0.333 & 0.407 & 0.591 \\
\hline SN9 & 0.285 & 0.279 & 0.270 & 0.250 & 0.738 \\
\hline
\end{tabular}

Table 3. Measurement model

\begin{tabular}{|c|c|c|c|c|}
\hline & Items & Loadings & AVE & $\mathrm{CR}$ \\
\hline \multirow[t]{5}{*}{ Convenience } & CON1 & 0.761 & 0.520 & 0.844 \\
\hline & $\mathrm{CON} 2$ & 0.767 & & \\
\hline & CON3 & 0.678 & & \\
\hline & CON4 & 0.690 & & \\
\hline & CON5 & 0.707 & & \\
\hline \multirow[t]{6}{*}{ Dependency } & DP1 & 0.643 & 0.533 & 0.872 \\
\hline & DP2 & 0.725 & & \\
\hline & DP4 & 0.705 & & \\
\hline & DP5 & 0.804 & & \\
\hline & DP6 & 0.770 & & \\
\hline & DP7 & 0.722 & & \\
\hline
\end{tabular}




\begin{tabular}{|c|c|c|c|c|}
\hline & Items & Loadings & AVE & $\mathrm{CR}$ \\
\hline \multirow[t]{5}{*}{ P Behavior } & PB1 & 0.686 & 0.566 & 0.865 \\
\hline & PB2 & 0.820 & & \\
\hline & PB3 & 0.603 & & \\
\hline & PB4 & 0.817 & & \\
\hline & PB5 & 0.809 & & \\
\hline \multirow[t]{5}{*}{ S Influence } & SI2 & 0.751 & 0.509 & 0.838 \\
\hline & SI3 & 0.754 & & \\
\hline & SI4 & 0.682 & & \\
\hline & SI7 & 0.713 & & \\
\hline & SI9 & 0.663 & & \\
\hline \multirow[t]{10}{*}{ S Need } & SN1 & 0.746 & 0.527 & 0.917 \\
\hline & SN10 & 0.789 & & \\
\hline & SN2 & 0.695 & & \\
\hline & SN3 & 0.663 & & \\
\hline & SN4 & 0.756 & & \\
\hline & SN5 & 0.852 & & \\
\hline & SN6 & 0.691 & & \\
\hline & SN7 & 0.707 & & \\
\hline & SN8 & 0.591 & & \\
\hline & SN9 & 0.738 & & \\
\hline
\end{tabular}

Note. SI1, SI5, SI6, \& DP3 were deleted due to low loading.

a: $\mathrm{CR}=(\Sigma \text { factor loading })^{2} /\left\{(\Sigma \text { factor loading })^{2}\right)+\Sigma$ (variance of error $\left.)\right\}$

b: AVE $=\Sigma$ (factor loading $)^{2} /(\Sigma \text { (factor loading })^{2}+\Sigma$ (variance of error $\left.)\right\}$

\subsection{The Discriminant Validity}

Next is to test the discriminant validity. The measurement model's discriminant validity is examined based on the criterion suggested by Fornell and Larcker (1981). The discriminant validity represents the extent to which a set of indicators discriminate a construct from other constructs in the model. This implies that good discriminant validity is achieved when the items share more variance with their constructs than the constructs share with other constructs more (Compeau et al., 1999). Table 4 showed the correlation matrix, the diagonal indicators are the square root of the AVE of the entire latent variables or constructs. Discriminant validity can be assumed if the diagonal indicators are greater than other off-diagonal indicators in their columns and rows. In this case, the discriminant validity is confirmed as exhibited in the in the correlation matrix.In total, the measurement model demonstrated adequate convergent validity and discriminant validity.

Table 4. Discriminant validity

\begin{tabular}{cccccc}
\hline & Convenience & Dependency & P Behavior & S Influence & S Need \\
\hline Convenience & 0.721 & & & & \\
Dependency & 0.283 & 0.730 & & & \\
P Behavior & 0.431 & 0.550 & 0.752 & & \\
S Influence & 0.214 & 0.364 & 0.271 & 0.714 & \\
S Need & 0.378 & 0.440 & 0.435 & 0.353 & 0.726 \\
\hline
\end{tabular}

\subsection{Assessment of the Structural Model}

After the assessment of the measurement model, the structural model, then evaluated to test the hypotheses. The structural model comprises of the hypothesized relationship between the model's exogenous and endogenous variables. It shows how well the theoretical model predicts the hypothesized paths. The bootstrapping procedure 
(500 resamples) was applied to generate the path coefficients and their corresponding t-values; which then enabled inferences to be made by determining the statistical significance of each path coefficient. Table 5 and Figure 2 show the results of testing the structural model.

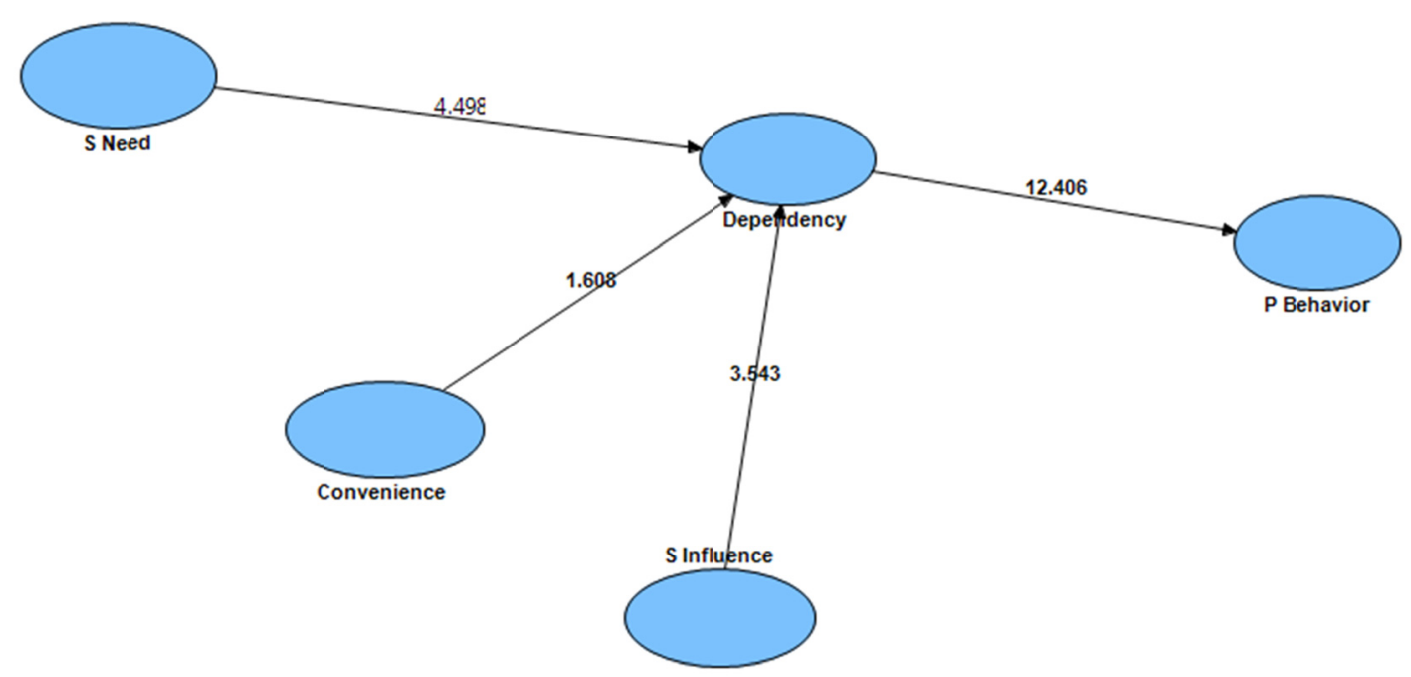

Figure 2. The structural model

\subsection{Predictive Power of the Model}

Following the assessment of the measurement model, the quality of the structural model can be assessed by $\mathrm{R}^{2}$. $\mathrm{R}^{2}$ indicates the amount of variance in the endogenous variable could be explained by the exogenous variables (Barclay et al., 1995). Based on the results reported in Table 5, the $\mathrm{R}^{2}$ of the Consumer dependency was found to be 0.254 indicating that the three exogenous variables, namely Convenience, Social needs and Social influence together explained $25.4 \%$ of the variance in the consumer dependency. In turn, the variable Consumer dependency could account for $30.3 \%$ of the variance in Purchase Behaviour. Based on the assessment criterion suggested by Cohen (1988), 0.26 substantial, 0.13 moderate and 0.02 weak; one of the values is considered moderate and the other value of the $\mathrm{R}^{2}$ is considered substantial.

Table 5. Predictive Power of the Model

\begin{tabular}{cc}
\hline Endogenous & R Square \\
\hline Consumer dependency & 0.254 \\
Purchase Behaviour & 0.303 \\
\hline
\end{tabular}

\subsection{Goodness of Fit (GoF) of the Model}

A global fit measure (GoF) assessment was also conducted to investigate the global validation of PLS model (Chin, 1998). The Tenenhaus et al. (2005) global goodness of fit (GoF) index was applied to the model.This measure is the geometric mean of the average variance extracted and the average $R^{2}$ for the endogenous variables. The following formula is used to compute GoF.

$$
\text { Gof }=\sqrt{\left(\overline{R^{2}} \times \overline{A V E)}\right.}
$$

Based on the results obtained, the GoF value was 0.384 which was calculated as in the following:

$$
\text { Gof }=\sqrt{(0.278 \times 0.148}=0.384
$$


On the basis of the results, the GoF value of 0.384 for the research model was obtained. Then, the result of the model is compared with Wetzels et al.,'s. (2009) baseline values of $\mathrm{GoF}$ ( small $=0.1$, medium $=0.25$, large $=0.36$ ). It can be concluded that the model's GoF measure is large and adequate of global PLS model validity.

\subsection{The Structural Model and Hypothesis Testing}

After successfully confirming the measurement model's validity and reliability, the next stage is to run PLS algorithm and Bootstrapping algorithm in SmartPLS 2.0 in order to test the hypothesized relationship.

Table 6. Hypothesis Testing Result

\begin{tabular}{cccccc}
\hline Hypothesis & Path & Std Beta & Std Error & t-Value & Decision \\
\hline H1 & Convenience - D Dependency & 0.114 & 0.071 & 1.608 & Not Supported \\
H2 & S Need -> Dependency & 0.316 & 0.070 & $4.498^{* *}$ & Supported \\
H3 & S Influence -> Dependency & 0.228 & 0.064 & $3.543^{* *}$ & Supported \\
H4 & Dependency -> P Behavior & 0.550 & 0.044 & $12.406^{* *}$ & Supported \\
\hline
\end{tabular}

${ }^{* *} \mathrm{p}<0.01,{ }^{*} \mathrm{p}<0.05$

Table 6 shows the result of hypothesis testing. From the analysis, it was found that the relationships between all the exogenous variables Social Needs $(\beta=0.316, p<0.01)$; Social Influence $(\beta=0.228, p<0.01)$ except for Convenience, and Consumer Dependency were positively and statistically significant. In addition, results show that Consumer Dependency $(\beta=0.552, p<0.01)$ was positively related to Purchase Behaviour. However, Convenience $(\beta=0.114, p>0.05)$ are not significantly related to Consumer Dependency. Through this analysis, hypotheses $\mathrm{H} 2, \mathrm{H} 3$, and $\mathrm{H} 4$ were confirmed, while hypotheses $\mathrm{H} 1$ was not supported.

\section{Discussion and Conclusions}

\subsection{Antecedents of Dependency}

Hypotheses $\mathrm{H}_{2}$ stated that social needs have a positive relationship with consumers' dependency on smartphone usage. The results of our study on hypotheses $\mathrm{H} 2$ showed a significant result which supports the hypotheses. This result is in line with the research findings of Ting et al. (2011) which reported that social needs lead to dependency on smartphone usage. Relatedly, Leung and Wei (2000) reported that the use of mobile phone is for affection and sociability purposes. Similarly, Balahkrishnan and Raj (2012) also suggested that the uses of mobile phones or telephones are social oriented and social motivated.

The concept of social need in this study refers to the need to communicate and stay connected with others. Almost all of today's smartphones are equipped with social networking applications such as Facebook, twitter and Myspace (Ting et al., 2011) which allows users to instantly get connected and stay connected to their favorite social networking sites instantly. Through this function consumers could get live updates from friends and family whenever and wherever they are. Balakrishnan and Raj (2012) reported that mobile phones are regarded as the extension of oneself, where communication among users was not tied to a physical location. Furthermore, certain smartphones, such as the iPhone, have live chatting application built-in to their smartphone; and live chatting and video calling among iPhone users are free via Wi-Fi or their data network. Based on the respondent profile, iPhone users stand as the second largest group of respondents, which is slightly below Samsung users. On top of that, local telecommunication service providers are selling smartphones at cheaper prices by taking up monthly subscription plans which include the data plan (Euromonitor, 2011). This makes it more affordable for more users to own a smartphone that comes with a data plan which allows access to the internet, thus enabling the user to stay connected with the important people in their lives. As what Dresler-Hawke and Mansvelt (2008) suggested, the mobile phone has become an important thing in the lives of youths today, as a necessary part of social communication which allows them to communicate through updating their social networks. Through social websites, live updates of status or information of friends or events or even emails is just within a click away, accessible whenever you want. Most importantly, all these functions are free via smartphone through Wi-Fi or their current data plan. Many users nowadays use social websites, especially Facebook or twitter, to inform their peers or affiliates about happenings, events or even meetings and discussions. This creates the need for consumers to keep up-to-date via these social websites, especially when they are on the go with their smartphone. As what Wei (2008) suggested, mobile phones have gone beyond voice. 
The results of this study also showed that the hypothesis $\mathrm{H}_{3}$ - social influence has a positive relationship with dependency on smartphone usages - was significant. As stated earlier, social influence was defined by Weber and Villebonne (2002) as a cultural environment that can influence one's behavior as well as influence the reasons why and how people live. $\mathrm{Lu}$ and Wang (2008) further expanded the concept of social influence to include its impact on the user's perception and behavior through two distinct constructs, i.e. the subjective norms and descriptive norms. Past researchers described subjective norms as the social pressures to perform or not to perform a specific behavior when an individual is faced with decisions to behave in a certain way (Fishbein \& Ajzen, 1975; Lu \& Wang, 2008; Bearden, Metemeyer, \& Teel, 1989; Pookulangara \& Koesler, 2011). In relation to this, Fishbein and Ajzen (1975) further explained that the perceived pressure to perform a given behavior is related to the expectations of a person's family, friends, or the society at large. In our study, the subjective norm is one of the dimensions of social influence. Therefore, our finding is partially in line with Ting et al. (2011) on their finding on social influence as a single dimension construct that leads to dependency.

This result suggested that pressure from friends and family would influence the dependency on smartphone. Peer pressure is one of the most influential pressures, especially on youth towards their behavior (Perrine and Aloise-Young, 2004). The pressure of the society indeed had great impact on our respondents to own and be dependent on smartphones, even for those with a low monthly salary. Yang and Jolly (2009) discussed that people in Asian countries are more susceptible towards a collective type of culture whereas Europeans are more individualistic in nature. As such, it stands to reason that Asians are more influenced by their social surroundings. This conforms to this study's finding, where social pressures are viewed as factors that lead to the smartphone dependency, particularly when they are greatly pressured by friends and family to own a smartphone to stay connected. Since the majority of smartphones today have built-in social applications and messaging applications, for example iPhone and Blackberry both have free messaging service among the similar phone brand, pressure from friends and family were likely to influence one's decision to own a similar smartphone that would allow for cheaper connectivity among each other.

As for hypotheses $\mathrm{H}_{1}$, the relationship between convenience and dependency, it was rejected. This implies that time utilization does not have a positive relationship with dependency on smartphone usage. This is in contradiction with research findings by Ting et al. (2011) where they found that convenience does lead to dependency on smartphone usage. They suggested that consumer demand for convenience is higher due to time scarcity. However, they conceptualized convenience as a single dimension construct. Time utilization in this study context is referred to as being practical and effective of use of the smartphone that help save time. Harvel (2006) and Berry et al. (2002) both suggested convenience was related to time issues. Indeed smartphones that do come with ample applications provide great convenience and can assist its users in undertaking their daily tasks quickly. This study's rejected hypothesis was explained by Karimuddin (2012) in that he revealed that a study done by Nielsen Telecom Industry Group showed that location based service of smartphone utilization do exist in mature markets such as in Korea, Japan and Singapore, while growing markets such as Indonesia and Malaysia, its usage are more focused on social media and search applications.

\subsection{The Outcome of Dependency - Purchase Behavior (Continuous Purchase)}

The results stated in Table 6 showed that hypotheses $\mathrm{H} 4$ was significant at $\mathrm{p}<0.01$. Therefore, the hypotheses of dependency of consumer on smartphone have a positive relationship with their purchase behavior was accepted. This means dependency on smartphone would lead to consumer purchase behavior. This study's finding is in line with previous research findings by Ting et al. (2011). Purchase behavior in this study refers to as repeat purchase or future repurchase of smartphone. The result of our study is also in line with research findings by Alcaniz et al. (2008), which reported a significant relationship of online information dependency to future online purchase intention. This showed that since consumers were dependent on a product, it would be unlikely for them to switch and thus remain loyal and continue usage of the product that they have; particularly since they have already adapted and are familiar with it. Kuhlmeier and Knight (2003) showed that the past positive experience of consumers will lead to future purchase behavior. This supports the findings of our study that consumers will show dependency towards a product that they were satisfied with their usage and to which they had adapted a routine or habit towards the product that they were using; thus leading to future purchase behavior. For example a consumer that uses a social network account through their smartphone application will be unlikely to change to a "normal" mobile phone as they had been using and depending on smartphone as a means of connectivity with their existing mobile application account all this while. Patwardhan and Yang (2003) and Mafe and Blas (2006) also showed a significant relationship of internet dependency on future online purchase behavior. Ball-Rokeach (1985) reported that purchases of product were intensified when individual dependency is high. The user's dependency towards a media like internet, television or smartphone in the long run creates a confidence and 
satisfaction within the consumer towards the product through dependency. It would then lead to future purchase behavior based on their past experience with the product that gives them the confidence and satisfaction.

\subsection{Conclusion}

Since there is a growing trend of smartphone usage in Malaysia, the smartphone industry is also growing in its importance and viewed as a profiting industry in the country. It is clear that the newer models of mobile phones available in the market today offers more than just call-and-text features, but also includes various useful features such as photo taking, voice recording, file organizing and the like, thus making them popular to own amongst the everyday consumers. As a result of its growing popularity, it is important for academicians and marketers to understand the underlying causes and outcomes behind this smartphone dependency phenomenon in order to understand consumer behavior. It is particularly important for marketers to understand customers' dependency to smartphone usage in order to sustain sales of smartphones and its share in the market. This study was undertaken to understand the important factors that can influence dependency on smartphone usage and on the expected outcome of the dependency to purchasing behavior. This was done through the Theory of Uses and Gratification, which was used to justify and explain factors that motivate people's dependency on smartphone, and the Theory of Media Dependency, which was used to explain dependency and purchasing behavior.

Based on the gratification theory, the motivation of use of smartphones was proposed to cause dependency on smartphone. With that, the antecedents of smartphone dependency were proposed to be entertainment, social needs, social influence and convenience. The outcome of the smartphone dependency was proposed to be a consumer purchase behavior. This is in line with Karimuddin's (2012) statement that the Malaysian market for smartphone was in its growing stage and thus, consumers' use of smartphones are still mainly for social connectivity and search purposes. Whereas, Loh (2011) suggested that people in Malaysia still prefer to use their laptop or personal computer. As suggested by Alcaniz et al. (2008), when the benefit of smartphone was greatly perceived and valued, dependency on smartphone would definitely increase. It is predicted that in the future, as the market matures, there will be more reason for consumers to be dependent on smartphone usage which in turn leads to future purchase behavior. Since the smartphone is still a growing trend and Malaysia is a growing market for the smartphone industry, it is beneficial to understand the different cultural needs on mobile phone usage as it could help local marketers of smartphones to promote, advertise and sell their product within the area.

\section{References}

Alcaniz, B. E., Mafe, C. R., Manzano, J. A., \& Blas, S. S. (2008). Influence of online shopping information dependency and innovativeness on internet shopping adoption. Online Information Review, 32(5), 648-667. http://dx.doi.org/10.1108/14684520810914025

Amato, S., Esposito Vinzi, V., \& Tenenhaus, M. (2004, March 24). A global goodness-of-fit index for PLS structural equation modeling. Oral Communication to PLS Club, HEC School of Management, France.

Auter, P. J. (2007). Portable social groups: willingness to communicate interpersonal communication gratifications, and cell phone use among young adults. International Journal Mobile Communication, 5(2), 139-156.http://dx.doi.org/10.1504/IJMC.2007.011813

Bagozzi, R.P., Yi, Y., \& Phillips, L. W. (1991). Assessing construct validity in organizational research, Administrative Science Quarterly, 36, 421-478. http://dx.doi.org/10.2307/2393203

Balakrishnan, V., \& Raj, R. G. (2012). Exploring the relationship between urbanized Malaysian youth and their mobile phones: A quantitative approach. Journal of Telematics and Informatics, 29(3), 263-272. http://dx.doi.org/10.1016/j.tele.2011.11.001

Ball-Rokeach, S. J. (1985). The origins of individual media system dependency: a sociological framework. Communication Research, 12(4), 485-510. http://dx.doi.org/10.1177/009365085012004003

Barclay, D. W., Thompson, R., \& Higgins, C. (1995). The Partial Least Squares (PLS) Approach to Causal Modeling: Personal Computer Adoption and Use an Illustration. Technology Studies, 2(2), 285-309.

Bearden, W. O., Netemeyer, R. G., \& Teel, J. E. (1989). Measurement of consumer susceptibility to interpersonal influence. Journal of Consumer Research, 15(4), 473-481.

Berry, L. L., Seiders, K., \& Grewal, D. (2002). Understanding service convenience. Journal of Marketing, 66(3), 1-17. http://dx.doi.org/10.1509/jmkg.66.3.1.18505

Brown, L. G. (1993). Convenience in Services Marketing. Journal of Services Marketing, 4(1), 53-59. http://dx.doi.org/10.1108/EUM0000000002505 
Chin, W. W. (1998) .The partial least squares approach to structural equation modeling. In G. A. Marcoulides (Ed.), Modern methods for business research (pp. 295-336). Mahwah: Lawrence Erlbaum.

Cohen, J. (1988). Statistical power analysis for the behavioral sciences (2nd ed.). Hillsdale, Lawrence Erlbaum Associates, NJ.

Compeau, D. R., Higgins, C. A., \& Huff, S. (1999). Social Cognitive Theory and individual Reactions to Computing Technology - A Longitudinal-Study. MIS Quarterly, 23(2), 145-158. http://dx.doi.org/10.2307/2 49749

Dresler-Hawke, E., \& Mansvelt, J. (2008). Mobile Phone: Enhancing social communication in young adult's lives. Australian and New Zealand Marketing Academy Conference. Sydney, Australia.

Euromonitor. (2010). Smartphones: Not just iPhones, but a boomerang movement. Retrieved April 3, 2012, from http://www.portal.euromonitor.com.ezproxy.ums.edu.my/Portal/Pages/Search/SearchResultsList.aspx

Euromonitor. (2011). Mobile Phones in Malaysia. Retrieved April 3, 2012, from http://www.portal.euromonitor. com.ezproxy.ums.edu.my/Portal/Pages/Search/SearchResultsList.aspx

Fishbein, M., \& Ajzen, I. (1974). Belief, Attitude, Intention and Behavior: An Introduction to Theory and Research. Reading, MA:Addison-Wesley.

Fornell, C., \& Larcker, D. F. (1981). Evaluating structural equation models with unobservable variables and measurement error. Journal of Market Research, 18(1), 39-50. http://dx.doi.org/10.2307/3151312

Hair, J. F., Black, W. C., Babin, B. J., \& Anderson, R. E. (2010). Multivariate Data Analysis. Upper Saddle River, NJ: Prentice-Hall.

Hahn, J. (2010). Information seeking with Wikipedia on Ipod Touch. Reference Service Rewiew, 38(2), 284-298. http://dx.doi.org/10.1108/00907321011045043

Harvel, L. D. (2006). Convenience is not enough. Innovative Higher Education, 31(3), 161-174. http://dx.doi.org/10.1007/s10755-006-9018-4

Haverila, M. (2011). Mobile phone feature preferences, customer satisfaction and repurchase intent among male users. Australasian Marketing Journal, 19(4), 238-246.http://dx.doi.org/10.1016/j.ausmj.2011.05.009

Hawkins, D. I., Mothersbaugh, D. L., \& Mookerjee, A. (2010). Consumer Behavior: Building Marketing Strategy (11th ed). New Delhi: Tata McGraw Hill.

Holub, S. F., Green, M. C., \& Valenti, S. P. (2010). The smartphone: The tax practitioner's portable office. Tax adviser, 4l(3), 206-208.

Hooper, V., \& Zhou, Y. (2007). Addictive, dependent, compulsive? A study of mobile phone usage. $20^{\text {th }}$ Bled eConference eMergence: Merging and Emerging Technologies, Processes, and Institutions, June 4-6, 2007, Bled, Slovenia.

Karimuddin, A. (2012). Nielson's Founds on Asia's Smartphones Utilization. Retreived July 17, 2012, from http://dailysocial.net/en/2012/06/25/nielsen\%E2\%80\%99s-found-on-smartphone-utilization-in-asia/

Karlson, A. K., Meyers, B. R., Jacobs, A., Johns, P., \& Kane, S. K. (2009). Working Overtime: Patterns of Smartphone and PC Usage in the Day of an information Worker. Proceeding of the $7^{\text {th }}$ International Conference on Pervasive Computing (pp. 398-405). University of Washington Seattle.

Klobas, J. E., \& Clyde, L. A. (2001). Social influence and internet use. Library Management, 22(1), 61-67. http://dx.doi.org/10.1108/01435120110358943

Kong, C. M. (2006). Relationship Marketing in a Globalised World: Are you Ready? Kuala Lumpur: Utusan Publication.

Kuhlmeier, D., \& Knight, G. (2003). Antecedents to internet-based purchasing: a multinational study. International Marketing Review, 22(4), 460-473. http://dx.doi.org/10.1108/02651330510608460

Leung, L. (2007). Unwillingness-to-communicate and college students' motives in SMS mobile messaging. Journal of Telematics and Informatics, 24(2), 115-129. http://dx.doi.org/10.1016/j.tele.2006.01.002

Leung, L., \& Wei, R. (1998). The gratification of pager use: sociability, information-seeking, entertainment, utility, and fashion and status. Telematics and Informatiocs, 15(4), 253-264. http://dx.doi.org/10.1016/ S0736-5853(98)00016-1

Leung, L., \& Wei, R. (2000). More than just talk on the move: Uses and gratifications of the cellular phone. 
Journalism and Mass Communication Quarterly, 77(2), 308-320. http://dx.doi.org/10.1177/107769 900007700206

Lim, Y., Wong, P. M., Zolkepli, F., \& Rashvinjeet, S. B. (2012). Marital issues among problems caused by smartphone addiction. Retrieved June 20, 2012, from http://thestar.com.my/news/story.asp?file=/2012/2/ 12/nation/10723793\&sec $=$ nation

Lin, C. H., Sher, P. J., \& Shih, H. Y. (2005). Past progress and future directions in conceptualizing customer perceived value. International Journal of Service Industry Management, 16(4), 318-336. http://dx.doi.org/10.1108/09564230510613988

Loges, W. (1994). Canaries in the Coal Mine: Perceptions of Threat and Media System Dependency Relations. Communication Research, 21(5), 5-23. http://dx.doi.org/10.1177/009365094021001002

Loh, J. (2011). Tablets, smartphones ownership on the rise. Retrieved July 16, 2012, from http:/biz.thestar.com.my/news/story.asp?file=/2011/10/25/business/9763410\&sec=business

Lu, H. P., \& Wang, S. (2008). The role of Internet addiction in online game loyalty: an exploratory study. Internet research, 18(5), 499-519. http://dx.doi.org/10.1108/10662240810912756

Mafe, C. R., \& Blas, S. S. (2006). Explaining Internet Dependency: An exploratory study of future purchase intention of Spanish Internet users. Internet Research, 16(4), 380-397. http://dx.doi.org/10.1108/10662240 610690016

Mafe, C. R., \& Blas, S. S. (2008). The impact of Television dependency on teleshopping adoption. Direct Marketing: An International Journal, 2(1), 5-19. http://dx.doi.org/10.1108/17505930810863608

Maslow, A. H. (1943). A theory of human motivation. Psychological Review, 50(4), 394-395. http://dx.doi.org/10.1037/h0054346

Mason, W. A., Conrey, F. R., \& Smith, E. R. (2007). Situating Social Influence Process: Dynamic, Multidirectional Flows of Influence within Social Networks. Personality and Social Psychology Review. 11(3), 279-300. http://dx.doi.org/10.1177/1088868307301032

Newberry, C. R., Klemz, B. R., \& Boshoff, C. (2003). Managerial implications of predicting purchase behavior from purchase intentions: a retail patronage case study. Journal of Services Marketing, 17(6), 609-620. http://dx.doi.org/10.1108/08876040310495636

Oliver, R. L. (1999). Whence consumer loyalty. Journal of Marketing, 63, 33-44. http://dx.doi.org/10.2307/ 1252099

Osman, M. A., Sabudin, M., Osman, A., \& Yen, T. S. (2011). Consumer behavior towards usage of smartphone in Malaysia. 2011 International Conference on Software and Computer Application IPCSIT, 1-2 July 2011, IACSIT Press: Singapore.

Park, Y., \& Chen, J. V. (2007). Acceptance and adoption of the innovative use of smartphone. Industrial management and Data System, 107(9), 1349-1365. http://dx.doi.org/10.1108/02635570710834009

Patwardhan, P., \& Yang, J. (2003). Internet dependency relations and online consumer behavior: A media system dependency theory perspective on why people shop, chat, and read news online. Journal of Interactive Advertising, 3(2), 57-69. http://dx.doi.org/10.1080/15252019.2003.10722074

Perrine, N. E., \& Aloise-Young, P. A. (2004). The role of self-monitoring in adolescents' susceptibility to passive peer pressure. Personality and Individual Differences, 37(8), 1701-1716. http://dx.doi.org/10.1016/j.paid. 2004.03.005

Pilstorm, M., \& Brush, G. J. (2008). Comparing the Perceived Value of Information and Entertainment Mobile Services. Psycology \& Marketing, 25(8), 732-755.http://dx.doi.org/10.1002/mar.20236

Pookulangara, S., \& Koesler, K. (2011). Cultural influence on consumer's usage of social networks and its' impact on online purchase intention. Journal of Retailing and Consumer Services, 18(4), 348-354. http://dx.doi.org/10.1016/j.jretconser.2011.03.003

Podsakoff, P. M., MacKenzie, S. B., Lee, J.-Y., \& Podsakoff, N. P. (2003). Common method biases in behavioral research: A critical review of the literature and recommended remedies. Journal of Applied Psychology, 88(5), 879-903. http://dx.doi.org/10.1037/0021-9010.88.5.879

Podsakoff, P. M., \& Organ, D. W. (1986). Self-reports in organizational research: Problems and prospects. Journal of Management, 12(4), 69-82. http://dx.doi.org/10.1177/014920638601200408 
Stafford, T. F., \& Gillenson, M. L. (2004). Motivations for Mobile Devices: Uses and Gratifications for M-Commerce. Proceedings of the Third Annual Workshop on HCI Research in MIS. December 10-11, 2004, Washington, D. C.

Stephens, D. C. (2000). The Maslow Business Reader. New York: John Wiley \& Sons.

Tenenhaus, M., Esposito, V., Chatelin, Y. M., \& Lauro, C. (2005). PLS path modelling. Computational Statistics \& Data Analysis, 48(1), 159-205.http://dx.doi.org/10.1016/j.csda.2004.03.005

Tikkanen. I. (2009). Maslow's hierarchy and pupils' suggestions for developing school meals. Nutrition \& Food Science, 39(5), 534-543. http://dx.doi.org/10.1108/00346650910992196

Ting, D. H., Lim, S. F., Patanmacia, T. S., Low, C. G., \& Ker, G. C. (2011). Dependency on smartphone and the impact on purchase behavior. Young Consumers, 12(3), 193-203. http://dx.doi.org/10.1108/1747 3611111163250

Uncles, M. D., Dowling, G. R., \& Hammond, K. (2003). Customer loyalty and customer loyalty programme. Journal of consumer marketing, 20(4), 294-316. http://dx.doi.org/10.1108/07363760310483676

Weber, J. M., \& Villebonne, J. C. (2002). Difference in purchase behavior between France and the USA: the cosmetic industry. Journal of Fashion Marketing and Management, 6(4), 396-407. http://dx.doi.org/10.1108/13612020210448673

Wetzels, M., Odekerken-Schröder, G., \& Oppen, C. V. (2009). Using PLS path modeling for assessing hierarchical models: Guidelines and empirical illustration. MIS Quarterly, 33(1), 177-195.

Wei, R. (2008). Motivations for using the mobile phone for mass communications and entertainment. Journal of Telematics and Informatics, 25(1), 36-46. http://dx.doi.org/10.1016/j.tele.2006.03.001

Wu, J. H., Wang, S. C., \& Tsai, H. H. (2010). Falling in love with online games: The uses and gratification perspective. Journals of Computers in Human Behavior, 26(6), 1862-1871. http://dx.doi.org/10.1016/j.chb. 2010.07.033

Yang, K., \& Jolly, L. D. (2009). The effects of consumer perceived value and subjective norm on mobile data service adoption between American and Korean consumers. Journal of Retailing and Consumer Service, 16(6), 502-508. http://dx.doi.org/10.1016/j.jretconser.2009.08.005

\section{Copyrights}

Copyright for this article is retained by the author (s), with first publication rights granted to the journal.

This is an open-access article distributed under the terms and conditions of the Creative Commons Attribution license (http://creativecommons.org/licenses/by/3.0/). 